\title{
Measuring User Engagement in Mobile Classroom Response System: A Case Study
}

\author{
Tek Yong $\operatorname{Lim}^{1(\bowtie)}$, Chia Ying Khor ${ }^{1}$, and Yin Bee Oon ${ }^{2}$ \\ ${ }^{1}$ Multimedia University, Cyberjaya, Malaysia \\ \{tylim, cykhor\}@mmu. edu.my \\ ${ }^{2}$ Universiti Malaysia Sarawak, Kota Samarahan, Malaysia \\ yinbee@unimas.my
}

\begin{abstract}
Mobile classroom response system, formerly known as clicker, is a promising technology to engage students in a lecture hall. Previous studies reported the positive effects of clickers on student engagement. However, most studies focused on patterns of cohort transitions using clickers during peer-instruction activities. This paper describes a mixed method approach to explore the dynamic of user engagement among undergraduate students in a local Malaysian university. Both interaction log and diary study were selected to track the pattern of ninety five registered students using mobile classroom response system across seven lecture weeks. Interaction logs were used to profile user type, participation type and submission type. The analysis of interaction logs revealed that seven visitors participated during lecture, only around $18 \%$ of registered students participated actively, registered students were more likely to answer all questions at the end of lecture compared to the beginning of lecture and middle of lecture. On the other hand, the analysis of diary entries provided qualitative information about user engagement attributes such focused attention, felt involvement, endurability, perceived usability and novelty. Both interaction $\log$ and students diary indicated that two registered students had positive engagement using mobile classroom response system during lecture.
\end{abstract}

Keywords: User engagement $\cdot$ Mobile classroom response system $\cdot$ Interaction $\log \cdot$ Diary study

\section{Introduction}

Technologies have been used to transform the students' learning experience in a lecture hall. For example, instructors adopted television and radio to capture the students' attention in the early days [1]. Then, computer and projector became the necessary tools in every lecture hall. However, these technologies are not design to encourage student participation in traditional lecture hall and the students are more likely to sit passively for entire lecture session. New mobile classroom response system has emerged as a promising technology to engage large audience using mobile devices [2].

Mobile classroom response system, formerly known as clicker [3], is a management tool for instructors to deliver an interactive lecture especially in a large classroom setting. This system is known under various names such as personal response system [4], student 